\title{
Uso racional de recursos naturais não-renováveis: aspectos biológicos, econômicos e ambientais
}

\author{
Rogério de Paula Lana ${ }^{1}$ \\ 1 Departamento de Zootecnia - UFV. Bolsista $1 B$ do CNPq; \\ RESUMO - Devido à limitação de novas terras para a agricultura, o seu desenvolvimento tem ocorrido com base em \\ aumento de índices de produtividade na produção animal e de plantas. Entretanto, efeitos negativos têm emergido, como a \\ excessiva utilização de recursos naturais não renováveis e a poluição ambiental. O objetivo deste trabalho foi demonstrar a \\ possibilidade do uso de modelos de saturação cinética na agricultura (produção de plantas e produção animal) para melhorar \\ a eficiência do uso dos recursos naturais não renováveis, evitar a completa depleção dos mesmos e minimizar os problemas \\ relacionados à poluição ambiental.
}

Palavras-chave: Lineweaver-Burk, Michaelis-Menten, nutrientes, produção animal, produção de plantas, saturação cinética

\section{Rational use of non renewable natural resources: biological, economical and environmental aspects}

\begin{abstract}
Due to limitations of new land areas for agriculture, its development has being based on increase in productive indexes in animal and plant production. However, negative effects have being emerged, as excessive utilization of non renewable natural resources and environmental pollution. The objective of this work was to demonstrate the possibility of use of models of saturation kinetics in agriculture (plant and animal production) to improve efficiency of use of non renewable natural resources, avoid complete depletion of them and minimize the problems related to environmental pollution.
\end{abstract}

Key Words: animal production, Lineweaver-Burk, Michaelis-Menten, nutrients, plant production, saturation kinetics

\section{Introdução}

O aumento da população humana e a demanda por melhoria da qualidade de vida têm pressionado a produção crescente de alimentos e de fontes alternativas de energia de origem vegetal em substituição ao petróleo. O progresso da agricultura tem ocorrido com base no aumento da produtividade animal e de plantas por unidade de área, que só tem aplicação quando apenas a disponibilidade de terras é o fator limitante. Entretanto, a eficiência de uso dos recursos limitantes (inclui também a água, os fertilizantes e o petróleo) deve ser levada em consideração.

Esta visão equivocada está levando à excessiva utilização dos recursos naturais não renováveis e a poluição ambiental. As reservas de fosfato no mundo que podem ser exploradas a baixo custo são suficientes para 40 a 100 anos e as reservas mundiais de potássio são suficientes para 50 a 200 anos. A situação é pior para os micronutrientes, em que as reservas de cobre e zinco são suficientes para 60 anos, manganês para 35 anos e selênio para 55 anos (Herring \& Fantel, 1993; Roberts \& Stewart, 2002; Aaron, 2005).

Além da depleção das reservas naturais, o uso excessivo de fertilizantes pode contribuir para a contaminação do solo e dos cursos d'água com nitrato (Angus, 1995; Bumb, 1995), acidificação do solo (Helyar \& Poter, 1989) e emissões de dióxido de carbono $\left(\mathrm{CO}_{2}\right)$, óxido nitroso $\left(\mathrm{N}_{2} \mathrm{O}\right)$ e amônia para a atmosfera. A poluição com nitrato tem sido uma atual preocupação na Europa e América do norte. A fertilização com fósforo e nitrogênio causa decréscimo na oxigenação da água pelo excessivo aumento na população de algas tóxicas nos oceanos (Kebreab et al., 2002).

A agricultura participa em $20 \%$ do aumento anual de emissão antropogênica de gases de efeito estufa, principalmente $\mathrm{CH}_{4}$ e $\mathrm{N}_{2} \mathrm{O}$. Aproximadamente $70 \%$ de todas as emissões antropogênicas de $\mathrm{N}_{2} \mathrm{O}$ são atribuídas à agricultura. A metodologia corrente usada no Canadá para estimar o fluxo de $\mathrm{N}_{2} \mathrm{O}$ é baseada na relação direta entre a emissão de $\mathrm{N}_{2} \mathrm{O}$ e a aplicação de fertilizantes nitrogenados (Lemke et al., 1998). 
Os possíveis efeitos deletérios das emissões de $\mathrm{N}_{2} \mathrm{O}$ são no aquecimento global e na destruição catalítica da camada de ozônio da estratosfera, onde o $\mathrm{N}_{2} \mathrm{O}$ retém 13 vezes mais calor que o metano $\left(\mathrm{CH}_{4}\right)$ e 270 vezes mais que o $\mathrm{CO}_{2}$ (Granli \& Bockman, 1994). O nível atmosférico de $\mathrm{N}_{2} \mathrm{O}$ tem aumentado de forma crescente desde 1960, associado com o aumento na utilização da fertilização nitrogenada (Bumb, 1995; Strong, 1995).

Um fenômeno preocupante sobre o uso dos recursos naturais não renováveis pode ser visualizado na chamada curva de Hubbert (Dr. Marion King Hubbert), que era um Geologista da Shell, e predisse em 1956 que a produção global de petróleo iria apresentar pico de produção no início do Século XXI (Hubbert Peak theory, http:// en.wikipedia.org/wiki/Hubbert_peak_theory, acessado em 02/03/2009), e que a curva de exploração segue o formato de um sino (Figura 1).

O fenômeno observado por Hubbert quanto à exploração de petróleo, se aplica à exploração de qualquer outro recurso natural não renovável, como o uso de fertilizantes, uso do solo e da água e, conseqüentemente, a produção de alimentos. Quanto mais persistente for a manutenção da exploração máxima do recurso, mais drástica é a queda na exploração das reservas restantes em um curto espaço de tempo, ocorrendo o chamado blackout ou queda brusca na taxa de produção (Figura 1). Portanto, a partir do pico de exploração, se não houver novas reservas a serem descobertas, alternativas para se produzir mais alimentos sem depender dos recursos vigentes, ou racionalização da exploração com base na eficiência de uso destes recursos, conseqüências catastróficas podem ocorrer com a humanidade em algum momento neste século, conforme previsto pelo Clube de Roma em 1972, na publicação conhecida como "The limits of growth" ou limites do crescimento (Meadows et al., 1972). O alerta do Clube de Roma foi lançado com base em modelo associando a

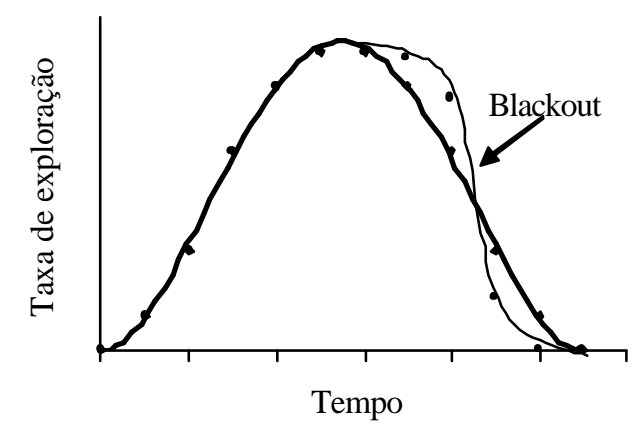

Figura 1 - Curva de Hubbert de exploração dos recursos naturais não renováveis e curva alterada pela manutenção artificial do pico de produção. industrialização acelerada, o rápido crescimento populacional, a depleção dos recursos naturais não renováveis, a subnutrição generalizada e a poluição ambiental.

Este trabalho teve como objetivo demonstrar a possibilidade do uso de modelos de saturação cinética para melhorar a eficiência do uso dos recursos naturais não renováveis e evitar a completa depleção dos mesmos, conforme previsto pela curva de Hubbert, e minimizar os problemas relacionados à poluição ambiental.

\section{Curva de crescimento de populações}

A curva de crescimento de populações de seres vivos na ausência de fatores que afetem a integridade física, a exemplo de doenças e predação, apresenta formato sigmóide, passando pela fase de latência, crescimento exponencial, platô e senescência ou morte. O platô ocorre devido ao fenômeno de saturação associado principalmente à depleção de nutrientes ou em alguns casos pela poluição do ambiente, que atuam como feedback no crescimento desordenado (Figura 2).

Para se ter uma idéia, uma bactéria com volume de $1 \mathrm{~mm}^{3}$ e tempo de duplicação de 20 minutos tem potencial de atingir uma biomassa muito maior que o planeta terra em apenas 48 horas ou 144 gerações (Russell, 2002; p.57-58). Portanto, as bactérias são os primeiros seres vivos do planeta, estão passando fome o tempo todo, e podem ser os sobreviventes de um colapso biológico, como aconteceu há 150.000 anos com os dinossauros e há 250.000 anos, quando mais de $90 \%$ dos seres vivos foram extintos, levando à formação das reservas de petróleo que estão sendo exploradas atualmente.

Outro exemplo de cessação de crescimento e morte da população pela poluição ambiental é na produção de silagem, onde as bactérias morrem e os nutrientes conservam para serem usados pelos ruminantes, com a acidez causada pelo

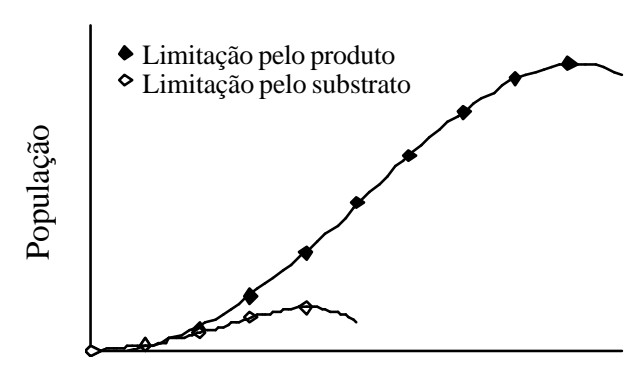

Tempo

Figura 2 - Curva de crescimento dos seres vivos em função da saturação pela limitação de nutrientes (desnutrição) ou produto do metabolismo (poluição ambiental). 
acúmulo de produtos de fermentação - os ácidos graxos voláteis.

Falar de crise de produção de alimentos nos leva de volta à teoria de Malthus, que apesar de alguns erros conceituais, irá assombrar ou perseguir a humanidade e todos os seres vivos para sempre. Conforme Malthus, a curva de crescimento populacional segue progressão geométrica e a produção de alimentos progressão aritmética, podendo levar à crise no abastecimento de alimentos em determinadas situações ou em determinadas épocas (Thomas Malthus, http://pt.wikipedia.org/wiki/ Thomas_Malthus, acessado em 02/03/2009).

Entretanto, ambos seguem naturalmente uma curva sigmóide até atingir o platô ou forma de um sino ou dupla sigmóide ao prolongar o tempo (a segunda é decrescente ou o espelho da primeira). A curva de crescimento da população é cumulativa, consequiência da soma das taxas anuais de crescimento (Figura 3), que depende da taxa anual de produção de alimentos (produtividade), que por sua vez é conseqüência da taxa anual de utilização do solo e de exploração dos recursos naturais não renováveis (fertilizantes e petróleo), que segue a curva de Hubbert. Alterações nestas curvas podem ser provocadas pelo homem ou naturalmente, como descobertas de novas tecnologias de produção de alimentos e morte (causadas por doenças, guerras, predação, etc.), que favorecem a abundância no suprimento de alimentos ou colapso no suprimento de alimentos, como proliferação de pragas e doenças nas plantas, mudanças climáticas, etc.

Conhecer melhor estes fenômenos nos leva a crer sobre a necessidade de se utilizar racionalmente os recursos naturais não renováveis. Os modelos de saturação cinética são importantes ferramentas geradas pela ciência para se avaliar a eficiência e permitir o uso racional dos recursos naturais não renováveis (Lana, 2005; Lana et al., 2005; Lana, 2007a,b; Lana et al., 2007a,b; Lana, 2008), evitando, assim, a completa depleção dos mesmos e o colapso no suprimento

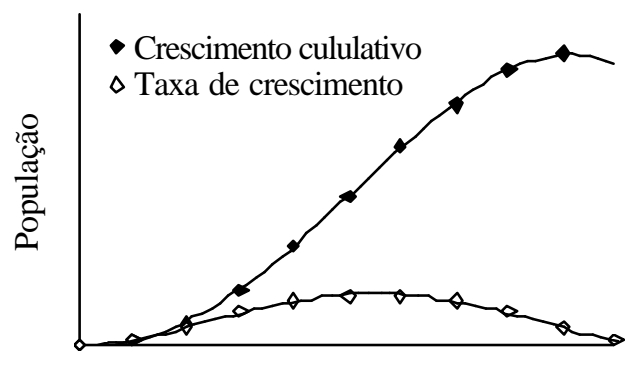

Tempo

Figura 3 - Crescimento populacional (cumulativo e taxa de crescimento) em função do tempo. de alimentos e de energia, com conseqüências dramáticas sobre nossa civilização, conforme previstos por Malthus, Hubbert e o Clube de Roma.

Modelos de repostas biológicas aos nutrientes

Os primeiros estudos sobre os fatores limitantes no crescimento das plantas foram desenvolvidos por Carl Sprengel em 1826 e 1828, e por Liebig em 1840, levando à reprovação da teoria do húmus e formulação da Lei do Mínimo (van der Ploeg et al., 1999). A Lei do Mínimo ou Lei da Resposta é associada à ausência de substituição de nutriente, resposta linear na produção pelo aumento na quantidade do fator limitante e um máximo platô de resposta, em que as plantas não respondem mais de forma satisfatória ao nutriente limitante.

Um marco posterior foi a lei dos rendimentos decrescentes de Mitscherlich (1909). A equação exponencial convexa de Mitscherlich, com um modelo que inclui um rendimento máximo assintótico, permite o cálculo do nível ótimo econômico de fertilização, baseado na relação benefício-custo.

O modelo de Michaelis-Menten (Michaelis \& Menten, 1913) foi desenvolvido para descrever a cinética enzimática no começo do século vinte. O modelo de Lineweaver-Burk (Lineweaver \& Burk, 1934), que consiste na obtenção da equação de regressão linear da recíproca de Y (atividade enzimática) em função da recíproca de $X$ (concentração de substrato) foi usado para obter as constantes cinéticas - $\mathrm{k}_{\mathrm{S}}$ (a quantidade de substrato necessária para atingir metade da atividade enzimática máxima) e $\mathrm{k}_{\text {max }}$ (atividade enzimática máxima) - do modelo de Michaelis-Menten.

Posteriormente, pesquisadores verificaram que a taxa de crescimento microbiano era dependente da concentração de substrato e ambos eram relacionados à cinética de saturação típica de sistemas enzimáticos (Monod, 1949; Russell, 1984).

Embora o uso da cinética de saturação para explicar as respostas aos nutrientes pelos seres vivos superiores não esteja sendo adotado (Morgan et al., 1975), o modelo de Michaelis-Menten permite explicar o relacionamento curvilíneo das respostas das plantas e animais aos nutrientes e o modelo de Lineweaver-Burk permite obter as constantes cinéticas - $\mathrm{k}_{\mathrm{s}}$ (a quantidade de substrato necessária para atingir metade da resposta máxima em taxa de crescimento ou produção - leite, lã, ovos, etc - máxima teórica) e $\mathrm{k}_{\max }$ (taxa de crescimento ou produção máxima teórica), segundo Lana et al. (2005).

A resposta das plantas e animais aos nutrientes como fenômeno de saturação tem importantes implicações em adição à taxa de retorno econômico decrescente e às 
estimativas de recomendações de nutrientes, como a conscientização sobre o uso excessivo de recursos naturais não renováveis; poluição do solo, água e ar; e o aquecimento global.

O conhecimento sobre a eficiência de utilização de fertilizantes na agricultura irá desempenhar um importante papel nas decisões políticas sobre o uso racional de recursos naturais não renováveis no futuro. As fontes de fertilizantes naturais têm de ser usadas com a máxima eficiência e com o mínimo de efeitos negativos no meio ambiente.

\section{Resposta marginal ou lei dos rendimentos decrescentes em plantas}

Recomendações de fertilização são na maioria baseadas no método de cálculos do requerimento de nutrientes da cultura e da contribuição mineral do solo. Os fertilizantes são então calculados para suprir as deficiências. Este método permite recomendar a menor dose que maximiza a produção. Entretanto, o método não indica a variação a ser feita na recomendação baseada na alteração da relação custo dos nutrientes e preço dos grãos. Também, não providencia informação direta do efeito da aplicação de outra dosagem que a recomendada (Makowski et al., 1999).

Tem sido utilizado um grande número de modelos empíricos para predizer as respostas aos nutrientes e calcular os níveis ótimos de nutrientes. Entre eles incluem o modelo de Mitscherlich, raiz quadrada (Mombiela et al., 1981; Sain \& Jauregui, 1993), exponencial, linear-mais-platô, linear-mais-hipérbola, quadrático e quadrático-mais-platô (Cerrato \& Blackmer, 1990; Bullock \& Bullock, 1994; Makowski et al., 1999, 2001).

O uso da cinética de saturação $\mathrm{p}$ ara explicar as respostas nutricionais aos nutrientes pelos seres vivos superiores tem sido raramente empregado (Morgan et al., 1975). O modelo de Michaelis-Menten não tem sido avaliado para se fazer recomendação de fertilização. Este modelo tem um grande potencial para ser usado na recomendação de uso de nutrientes na agricultura, ao considerar a eficiência de uso dos nutrientes e a lei dos rendimentos decrescentes de Mitscherlich (1909). Este modelo pode agregar importantes conceitos como as respostas aos diferentes níveis de nutrientes, a relação benefício-custo, a eficiência de uso de nutrientes, a racionalidade de uso de recursos naturais não renováveis e a conscientização sobre a poluição ambiental.

Regressões lineares da recíproca das respostas das plantas em função da recíproca do suprimento de nutrientes, metodologia conhecida como transformação de dados de Lineweaver-Burk (Lineweaver \& Burk, 1934; Champe \& Harvey, 1994), foram propostas por Lana et al. (2005) como segue:

$$
1 / \mathrm{Y}=\mathrm{a}+\mathrm{b} *(1 / \mathrm{X})
$$

em que $\mathrm{Y}=$ respostas das plantas (rendimento de grãos, $\mathrm{x}$ $1.000 \mathrm{~kg} / \mathrm{ha}) ; \mathrm{a}=$ intercepto; $\mathrm{b}=$ coeficiente de regressão linear; $X=$ quantidade de nutriente ( $\mathrm{kg} / \mathrm{ha} / \mathrm{ano})$.

A máxima produção teórica de grãos $\left(\mathrm{k}_{\max }\right)$ é obtida pela recíproca do intercepto (1/a). A quantidade de nutriente (X) necessária para atingir metade da resposta máxima teórica $\left(\mathrm{k}_{\mathrm{s}}\right)$ é obtida do modelo apresentado acima substituindo Y por 1/a x 50(\%) x 0,01 ou dividindo o coeficiente da regressão linear pelo intercepto (b/a).

A eficiência de uso de fertilizantes é calculada dividindo o acréscimo na produção de grãos $\left(\mathrm{Y}_{2}-\mathrm{Y}_{1}\right)$ pelo aumento na fertilização $\left(X_{2}-X_{1}\right)$, de um nível específico de fertilizante em relação ao nível anterior.

Simulações das respostas biológicas aos nutrientes na ausência ou presença de um segundo nutriente limitante são apresentadas na Figura 4 e Tabela 1, em que são esperadas mudanças no rendimento máximo $\left(\mathrm{k}_{\max }\right)$ e $\mathrm{k}_{\mathrm{s}} \mathrm{do}$ primeiro nutriente limitante (aumento, sem efeito ou decréscimo). A Figura 4A ilustra quatro tipos de respostas na produção e modelos de dupla-recíproca são apresentados na Tabela 1 e Figura 4B, demonstrando a combinação de dois valores de $\mathrm{k}_{\max }$ por dois de $\mathrm{k}_{\mathrm{s}}$.

Os melhores efeitos que um segundo nutriente limitante pode causar são pelo aumento do $\mathrm{k}_{\max }$, decréscimo do $\mathrm{k}_{\mathrm{s}}$, ou ambas as mudanças que podem ser ainda melhor. Entretanto, o tipo de resposta mais comum é pelo aumento de ambos $\mathrm{k}_{\max }$ e $\mathrm{k}_{\mathrm{s}}$. Aumento no $\mathrm{k}_{\max }$ pelo aumento na produtividade com um segundo nutriente aumenta a eficiência de uso do primeiro nutriente limitante (Figura 4C), mas este benefício decresce de forma acentuada pelo aumento da quantidade do primeiro nutriente limitante, especialmente quando $\mathrm{k}_{\mathrm{s}}$ é baixo.

A resposta das plantas à fertilização depende da fertilidade do solo, em que altas respostas ocorrem quando a fertilidade do solo é baixa (Figura 5A) e em baixo nível de fertilização, que é o principal fator que afeta a eficiência de uso dos fertilizantes (Figura 5B).

Equações de transformação de dados de LineweaverBurk foram usadas para explicar o efeito da fertilização e o efeito de um segundo fator no rendimento, $\mathrm{k}_{\mathrm{s}}, \mathrm{k}_{\max } \mathrm{e}$ eficiência de uso de fertilizantes (Tabelas 2, 3 e 4).

Quando calcário foi o segundo fator, houve mudança de $\mathrm{k}_{\mathrm{s}}$ e $\mathrm{k}_{\max }$ em 34 e $85 \%$; -75 e -10\%; e 33 e 22\% para soja fertilizada com $\mathrm{P}_{2} \mathrm{O}_{5}$ (Tabela 2). Calcário como um segundo fator mudou $\mathrm{k}_{\mathrm{s}}$ e $\mathrm{k}_{\mathrm{max}}$, respectivamente, em $-55 \mathrm{e}-12 \%$ para trigo fertilizado com $\mathrm{P}_{2} \mathrm{O}_{5}$, e em 9 e $87 \%$ para algodão fertilizado com $\mathrm{K}_{2} \mathrm{O}$.

Como visto acima, aumento ou decréscimo em $\mathrm{k}_{\max }$ é associado com o mesmo efeito em $\mathrm{k}_{\mathrm{s}}$, mas aumento no $\mathrm{k}_{\max }$ 

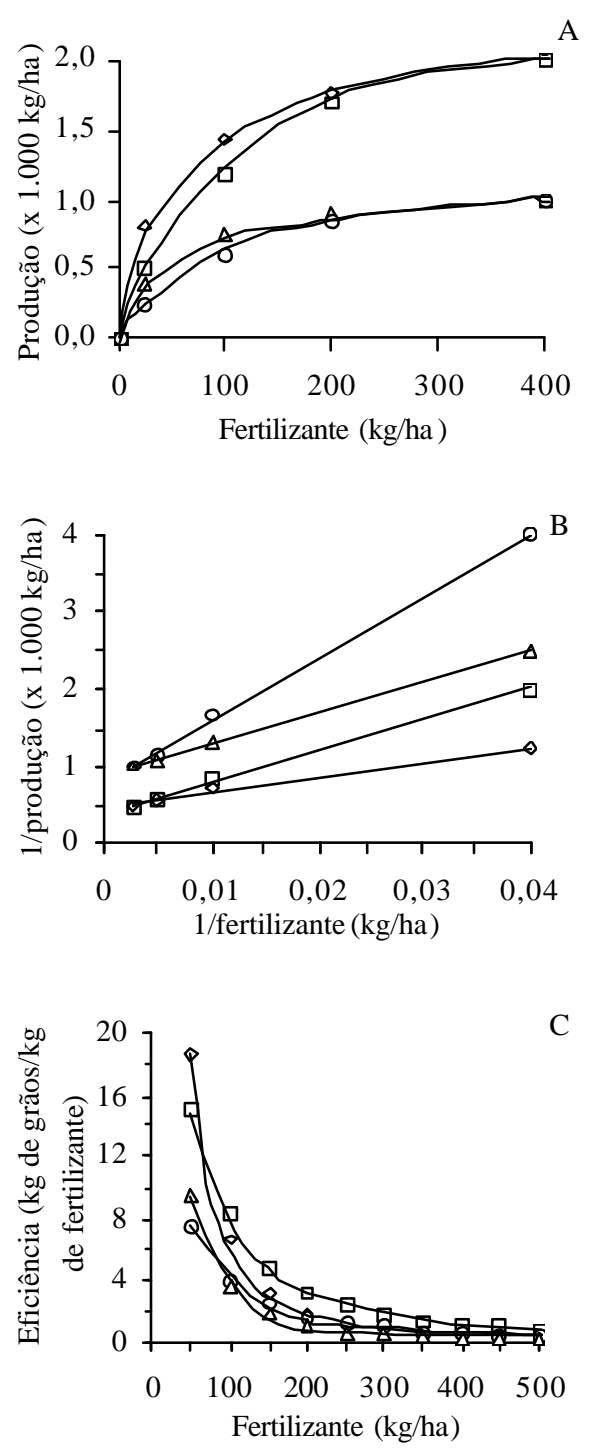

Figura 4 - Respostas biológicas aos nutrientes em função de um segundo nutriente limitante (A) - controle (O), decréscimo no $\mathrm{k}_{\mathrm{s}}(\boldsymbol{\Delta})$, aumento no $\mathrm{k}_{\max }(\boldsymbol{\square})$ e decréscimo no $\mathrm{k}_{\mathrm{s}}$ e aumento no $\mathrm{k}_{\max }(\bullet)$; recíproca da produção em função da recíproca do nível de fertilizante plotagem de Lineweaver-Burk (B); e efeito de um segundo nutriente limitante na eficiência de uso do primeiro $(\mathrm{C})$. associado a aumento exagerado em $\mathrm{k}_{\mathrm{s}}$ não é desejável porque requer mais fertilizante para atingir o platô. Em outras palavras, os maiores valores de $\mathrm{k}_{\mathrm{s}}$ apresentam maiores respostas ao uso de fertilizantes em alto nível de fertilização, mas pode não ser vantajoso devido ao aumento no custo com fertilização.

No caso da soja (Tabela 2), considerando US $\$ 1,208 / \mathrm{kg}$ de $\mathrm{P}_{2} \mathrm{O}_{5}$ e US\$0,178/kg de soja, é necessário $6,8 \mathrm{~kg}$ de soja para pagar $1 \mathrm{~kg}$ de fertilizante. Portanto, é viável usar de 50 a $100 \mathrm{~kg}$ de $\mathrm{P}_{2} \mathrm{O}_{5}$ na ausência de calcário e $100 \mathrm{~kg}$ de $\mathrm{P}_{2} \mathrm{O}_{5}$ na presença de calcário. Acima de $150 \mathrm{~kg}$ de $\mathrm{P}_{2} \mathrm{O}_{5}$, embora em alguns casos tenha ainda ocorrido reposta ao fertilizante, especialmente em altos valores de $\mathrm{k}_{\mathrm{S}}$, a resposta não é viável economicamente.
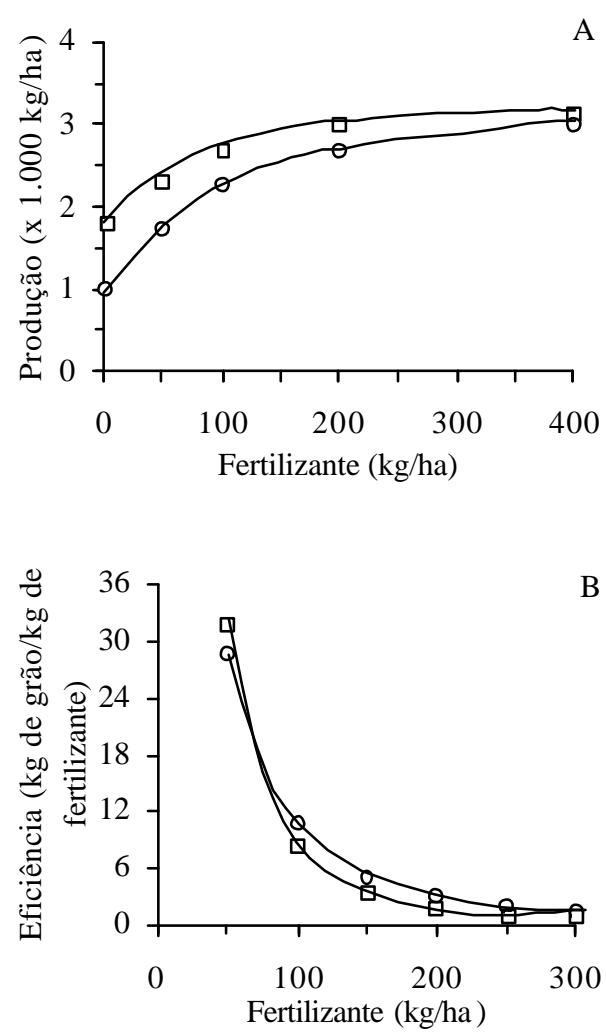

Figura 5 - Resposta da planta ao fertilizante em baixa $(\mathrm{O})$ e alta (ロ ) fertilidade do solo (A); e efeito da fertilidade do solo na eficiência de uso de fertilizante (B).

Tabela 1 - Constantes de regressão linear da recíproca da produção de grãos (x1.000 kg/ha) em função da recíproca da quantidade de fertilizantes ( $\mathrm{kg} / \mathrm{ha} / \mathrm{ano})$ em situações hipotéticas de altos ou baixos valores de constantes de saturação $\mathrm{k}_{\mathrm{s}}(\mathrm{kg}$ de fertilizante/ha) e $\mathrm{k}_{\max }(\mathrm{x} 1.000 \mathrm{~kg} / \mathrm{ha})$ - veja Figura 4B

\begin{tabular}{lcccccc}
\hline Equação & Símbolo & Intercepto (a) & Coeficiente (b) & $\mathrm{r}^{2}$ & $\mathrm{k}_{\mathrm{s}}$ & $\mathrm{k}_{\text {max }}$ \\
\hline 1 & $\mathrm{O}$ & 0,8163 & 79,789 & 1,00 & 1,00 & 1,2 \\
2 & $\mathbf{D}$ & 0,9195 & 39,591 & 1,00 & 43 & 1,1 \\
3 & $\mathbf{\square}$ & 0,4082 & 39,894 & 1,00 & 98 & 2,4 \\
4 & - & 0,4768 & 19,483 & 41 & 2,1 \\
\hline
\end{tabular}


Tabela 2 - Mudanças nas constantes de regressão linear da recíproca da produção de grãos (x1.000 kg/ha) em função da recíproca da quantidade de fertilizante $(\mathrm{kg} / \mathrm{ha} / \mathrm{ano})$, pelo segundo fator, e a respectiva eficiência de uso de fertilizantes ( $\mathrm{kg}$ de grãos $/ \mathrm{kg}$ de fertilizante)

\begin{tabular}{|c|c|c|c|c|c|c|c|c|}
\hline Produto & Fertilizante(kg/ha/ano) & Segundo fator ${ }^{1}$ & Intercepto (a) & Coeficiente (b) & $\mathrm{r}^{2}$ & $\mathrm{k}_{\mathrm{s}}{ }^{2}$ & $\mathrm{k}_{\max }{ }^{3}$ & Fonte de dados ${ }^{4}$ \\
\hline \multirow[t]{2}{*}{ Soja } & $\mathrm{P}_{2} \mathrm{O}_{5}$ & - & 0,7536 & 57,766 & 1,00 & 77 & 1,3 & 1 \\
\hline & & + & 0,4096 & 42,198 & 1,00 & 103 & 2,4 & 1 \\
\hline \multirow[t]{2}{*}{ Soja } & $\mathrm{P}_{2} \mathrm{O}_{5}$ & - & 0,3502 & 30,524 & 0,98 & 87 & 2,9 & 2 \\
\hline & & + & 0,3801 & 8,2987 & 0,99 & 22 & 2,6 & 2 \\
\hline \multirow[t]{2}{*}{ Soja } & $\mathrm{P}_{2} \mathrm{O}_{5}$ & - & 0,3103 & 3,6726 & 0,68 & 12 & 3,2 & 2 \\
\hline & & + & 0,2535 & 3,9962 & 0,53 & 16 & 3,9 & 2 \\
\hline \multirow[t]{2}{*}{ Trigo } & $\mathrm{P}_{2} \mathrm{O}_{5}$ & - & 0,4169 & 174,48 & 1,00 & 419 & 2,4 & 1 \\
\hline & & + & 0,4781 & 91,0 & 1,00 & 190 & 2,1 & 1 \\
\hline \multirow[t]{2}{*}{ Algodão } & $\mathrm{K}_{2} \mathrm{O}$ & - & 0,622 & 4,6865 & 0,91 & 7,5 & 1,6 & 1 \\
\hline & & + & 0,3284 & 2,7052 & 0,97 & 8,2 & 3,0 & 1 \\
\hline
\end{tabular}

Fertilizante (kg/ha)

Eficiência de uso de fertilizantes (kg de grãos/kg de fertilizante) $)^{5}$

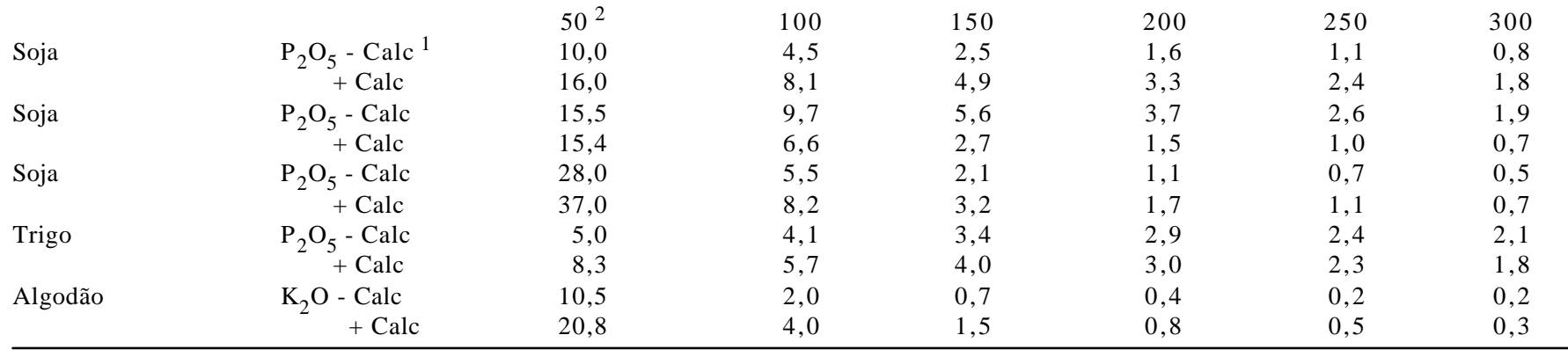

${ }^{1}$ Calcário: sem (-) ou com (+) 4.000 a $7.000 \mathrm{~kg} / \mathrm{ha} ;{ }^{2} \mathrm{~kg}$ de fertilizante/ha $-\mathrm{P}_{2} \mathrm{O}_{5}$ ou $\mathrm{K}_{2} \mathrm{O} ;{ }^{3}$ x $1.000 \mathrm{~kg} / \mathrm{ha}$ de grãos $;{ }^{4} 1=\mathrm{Malavolta}(1989)$, p.61, 275 e $283 ; 2=\mathrm{Oliveira}$ et al. (1982), p.36; ${ }^{5}$ Considerando US $\$ 1,208 / \mathrm{kg}$ de $\mathrm{P}_{2} \mathrm{O}_{5}$ e US $\$ 0,178 / \mathrm{kg}$ de soja, é necessário $6,8 \mathrm{~kg}$ de soja para pagar um kg de fertilizante. Eficiência menor que $6,8 \mathrm{~kg}$ de soja/kg de $\mathrm{P}_{2} \mathrm{O}_{5}$ não é viável. Estes cálculos podem ser usados para escolher o nível de fertilização.

Tabela 3 - Mudanças nas constantes de regressão linear da recíproca da produção de feijão (x1.000 kg/ha) em função da recíproca da quantidade de fertilizante $(\mathrm{kg} / \mathrm{ha} / \mathrm{ano})$, por um segundo fator

\begin{tabular}{|c|c|c|c|c|c|c|c|}
\hline $\begin{array}{l}\text { Fertilizante } \\
\text { (kg/ha/ano) }\end{array}$ & Segundo fator & Intercepto (a) & Coeficiente (b) & $\mathrm{r}^{2}$ & $\mathrm{k}_{\mathrm{s}}^{1}$ & $\mathrm{k}_{\max }^{2}$ & Fonte de dados ${ }^{3}$ \\
\hline $\mathrm{N}$ & $\begin{array}{c}\mathrm{P}_{2} \mathrm{O}_{5}(\mathrm{~kg} / \mathrm{ha}) \\
0 \\
40 \\
80 \\
100\end{array}$ & $\begin{array}{l}2,044 \\
0,782 \\
0,710 \\
0,630\end{array}$ & $\begin{array}{l}2,794 \\
8,516 \\
6,718 \\
8,205\end{array}$ & $\begin{array}{l}0,82 \\
1,00 \\
0,99 \\
1,00\end{array}$ & $\begin{array}{c}1 \\
11 \\
9 \\
13\end{array}$ & $\begin{array}{l}0,5 \\
1,3 \\
1,4 \\
1,6\end{array}$ & 1 \\
\hline $\mathrm{N}$ & $\begin{array}{c}\mathrm{P}_{2} \mathrm{O}_{5}(\mathrm{~kg} / \mathrm{ha}) \\
0 \\
50 \\
150 \\
250\end{array}$ & $\begin{array}{l}10,764 \\
2,5229 \\
1,3364 \\
0,9539\end{array}$ & $\begin{array}{l}183,36 \\
46,235 \\
15,623 \\
28,056\end{array}$ & $\begin{array}{l}0,23 \\
0,78 \\
0,99 \\
0,98\end{array}$ & $\begin{array}{l}17 \\
18 \\
12 \\
29\end{array}$ & $\begin{array}{l}0,1 \\
0,4 \\
0,7 \\
1,0\end{array}$ & 2 \\
\hline $\mathrm{P}_{2} \mathrm{O}_{5}$ & $\begin{array}{c}\mathrm{N}(\mathrm{kg} / \mathrm{ha}) \\
0 \\
30 \\
60\end{array}$ & $\begin{array}{l}1,3812 \\
0,8181 \\
0,6842\end{array}$ & $\begin{array}{l}6,7411 \\
8,8241 \\
10,186\end{array}$ & $\begin{array}{l}0,98 \\
1,00 \\
1,00\end{array}$ & $\begin{array}{c}5 \\
11 \\
15\end{array}$ & $\begin{array}{l}0,7 \\
1,2 \\
1,5\end{array}$ & 1 \\
\hline $\mathrm{P}_{2} \mathrm{O}_{5}$ & $\begin{array}{c}\mathrm{N}(\mathrm{kg} / \mathrm{ha}) \\
0 \\
50 \\
120\end{array}$ & $\begin{array}{l}1,3257 \\
1,0402 \\
0,6684\end{array}$ & $\begin{array}{l}180,38 \\
90,586 \\
132,74\end{array}$ & $\begin{array}{l}0,95 \\
1,00 \\
1,00\end{array}$ & $\begin{array}{c}136 \\
87 \\
199\end{array}$ & $\begin{array}{l}0,8 \\
1,0 \\
1,5\end{array}$ & 2 \\
\hline
\end{tabular}

${ }^{1} \mathrm{~kg}$ de fertilizante/ha; ${ }^{2}$ Toneladas de grãos/ha; ${ }^{3} 1$ = Bolsanello et al. (1975) e Oliveira et al. (1982), p.155; 2 = Malavolta (1989), p.273. 
Tabela 4 - Eficiência de uso de fertilizantes (kg de feijão/kg de fertilizante) calculado com base nas equações da Tabela 3

\begin{tabular}{|c|c|c|c|c|c|c|c|}
\hline \multirow[t]{2}{*}{ Fertilizante $(\mathrm{kg} / \mathrm{ha})$} & \multirow[t]{2}{*}{ Segundo fator } & \multicolumn{6}{|c|}{ Eficiência de uso de fertilizantes ( $\mathrm{kg}$ de grãos/kg de fertilizante) ${ }^{1}$} \\
\hline & & $50^{2}$ & 100 & 150 & 200 & 250 & 300 \\
\hline \multirow[t]{5}{*}{$\mathrm{N}$} & $\mathrm{P}_{2} \mathrm{O}_{5}(\mathrm{~kg} / \mathrm{ha})$ & & & & & & \\
\hline & 0 & 1,1 & 0,1 & 0,0 & 0,0 & 0,0 & 0,0 \\
\hline & 40 & 10,9 & 2,1 & 0,8 & 0,4 & 0,3 & 0,2 \\
\hline & 80 & 11,5 & 2,0 & 0,8 & 0,4 & 0,2 & 0,2 \\
\hline & 100 & 14,2 & 2,9 & 1,1 & 0,6 & 0,4 & 0,3 \\
\hline \multirow[t]{5}{*}{$\mathrm{N}$} & $\mathrm{P}_{2} \mathrm{O}_{5}(\mathrm{~kg} / \mathrm{ha})$ & & & & & & \\
\hline & 0 & 0,6 & 0,2 & 0,1 & 0,0 & 0,0 & 0,0 \\
\hline & 50 & 2,8 & 0,9 & 0,4 & 0,2 & 0,1 & 0,1 \\
\hline & 150 & 4,5 & 1,3 & 0,5 & 0,3 & 0,2 & 0,1 \\
\hline & 250 & 7,9 & 3,0 & 1,3 & 0,7 & 0,5 & 0,3 \\
\hline \multirow[t]{4}{*}{$\mathrm{P}_{2} \mathrm{O}_{5}$} & $\mathrm{~N}(\mathrm{~kg} / \mathrm{ha})$ & & & & & & \\
\hline & 0 & 5,4 & 0,6 & 0,2 & 0,1 & 0,1 & 0,0 \\
\hline & 30 & 12,2 & 2,0 & 0,7 & 0,4 & 0,2 & 0,2 \\
\hline & 60 & 15,3 & 2,9 & 1,1 & 0,6 & 0,4 & 0,3 \\
\hline \multirow[t]{4}{*}{$\mathrm{P}_{2} \mathrm{O}_{5}$} & $\mathrm{~N}(\mathrm{~kg} / \mathrm{ha})$ & & & & & & \\
\hline & 0 & 4,0 & 2,3 & 1,5 & 1,1 & 0,8 & 0,6 \\
\hline & 50 & 6,9 & 3,3 & 1,9 & 1,2 & 0,9 & 0,6 \\
\hline & 120 & 6,0 & 4,0 & 2,9 & 2,1 & 1,7 & 1,3 \\
\hline
\end{tabular}

${ }^{1}$ Considerando US $\$ 0,966 / \mathrm{kg}$ de N, US $\$ 1,208 / \mathrm{kg}$ de $\mathrm{P}_{2} \mathrm{O}_{5}$ e US $\$ 0,36 / \mathrm{kg}$ de feijão, é necessário 2,68 e 3,36 kg de feijão para pagar $1 \mathrm{~kg}$ de $\mathrm{N}$ ou $\mathrm{P}_{2} \mathrm{O}_{5}$. Eficiência pior que 2,68 ou 3,36:1 para $\mathrm{N}$ ou $\mathrm{P}_{2} \mathrm{O}_{5}$ não é economicamente desejável. Estes cálculos devem ser usados para escolher o nível de fertilização. ${ }^{2} \mathrm{Nível}$ de fertilizante (kg/ha) $\mathrm{N}$ nos dois primeiros casos ou $\mathrm{P}_{2} \mathrm{O}_{5}$ nos dois últimos casos.

Na produção de feijão (Tabela 3), o segundo fator $\left(\mathrm{P}_{2} \mathrm{O}_{5}\right)$ aumentou o $\mathrm{k}_{\text {max }}$ do nitrogênio de $0,1-0,5$ para 1,0 $1,6 \times 1.000 \mathrm{~kg} / \mathrm{ha}$ de feijão, mas também aumentou $\mathrm{o} \mathrm{k}_{\mathrm{s}}(1$ para 13 e 17 para $29 \mathrm{~kg} / \mathrm{ha}$ de nitrogênio). Quando o segundo fator foi o nitrogênio, este aumentou o $\mathrm{k}_{\max }$ do $\mathrm{P}_{2} \mathrm{O}_{5}$ de 0,70,8 para $1,5 \times 1.000 \mathrm{~kg} / \mathrm{ha}$ de feijão, mas também aumentou o $\mathrm{k}_{\mathrm{S}}\left(5\right.$ para 15 e 136 para $199 \mathrm{~kg} / \mathrm{ha}$ de $\mathrm{P}_{2} \mathrm{O}_{5}$ ). No segundo caso, os altos valores de $\mathrm{k}_{\mathrm{s}}$ para $\mathrm{P}_{2} \mathrm{O}_{5}$ proporcionaram pouca melhora na eficiência de uso deste fertilizante em baixo nível de fertilização (Tabela 4). A produção extra neste caso pode não ser suficiente para pagar a quantidade extra de fertilizantes.

\section{Resposta marginal em bovinos}

O ganho de peso de bovinos em crescimento em pastagem no período da seca comporta-se de forma curvilínea, em função do fornecimento do suplemento, em que a conversão do suplemento (kg de suplemento/kg de acréscimo no ganho de peso) piora com o aumento do fornecimento do mesmo (Lana et al., 2005; Keane et al., 2006; Lana, 2007b) (Figura 6).

A produção de leite por vacas suplementadas em pastagens ou em confinamento é também curvilínea em função do aumento no suprimento de concentrado (Figura 7A), em que o aumento marginal na produção de leite por $\mathrm{kg}$ de concentrado diminui com o aumento na quantidade de concentrado (Bargo et al., 2003; Pimentel et al., 2006a;
Sairanen et al., 2006; Lana et al., 2007a,b), conforme ilustrado na Figura 7B, e em alguns estudos a resposta em leite ao uso de concentrado foi satisfatória somente até $2-4 \mathrm{~kg}$ de concentrado/animal/dia (Fulkerson et al., 2006).

A resposta curvilínea pode também ser verificada em nutrientes específicos, como a observada resposta curvilínea positiva na produção de leite e curvilínea negativa na eficiência de uso de nitrogênio ao aumentar o teor de proteína bruta dietética de 11 para 19\% em vacas com média de $38 \mathrm{~kg}$ de leite/dia (Baik et al., 2006). No experimento $3 \mathrm{da}$ Figura 7, além da resposta decrescente na produção de leite, houve resposta decrescente na variação de peso corporal com o aumento no nível de concentrado $(0,20 ; 0,12$; e 0,095 $\mathrm{kg}$ extra de ganho de peso corporal por quilograma adicional de consumo de concentrado; Teixeira et al., 2006).

De acordo com o Biotechnology and Biological Sciences Research Council (1998), anteriormente conhecido como AFRC (Agricultural and Food Research Council), todos os sistemas alimentares em uso calculam os requerimentos dietéticos de energia e proteína que os animais requerem para satisfazer suas necessidades para mantença e um dado nível de produção. Entretanto, na prática, a situação é diferente, porque não existe nenhuma necessidade do fazendeiro satisfazer os requerimentos nutricionais das vacas se for contra os interesses econômicos. Então, fica evidente que estudos de resposta animal aos níveis crescentes de concentrados ou 

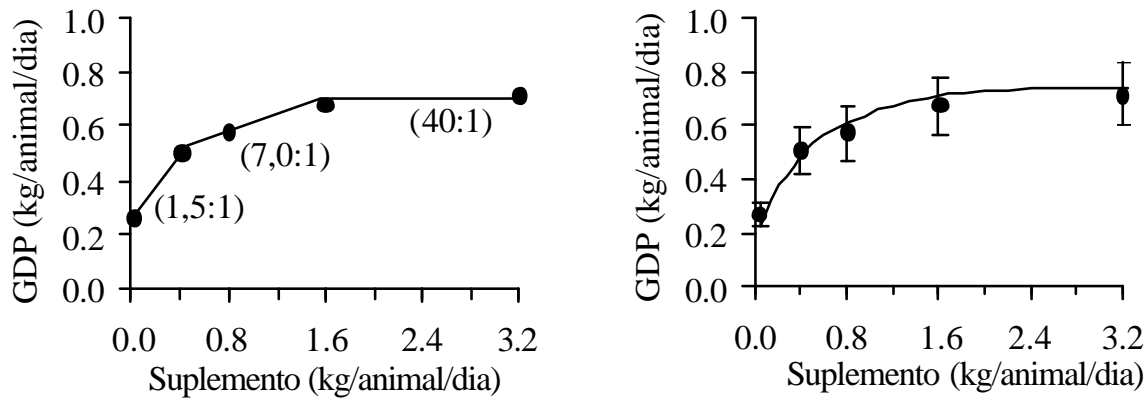

Figura 6 - Ganho de peso (GDP) de bovinos em crescimento em pastagem no período da seca, em função consumo diário de suplemento com $24 \%$ de PB, sendo que os valores entre parênteses representam o diferencial em quilogramas de suplemento fornecido diariamente dividido pelo diferencial de ganho de peso, em relação ao tratamento anterior (Lana, 2005; Lana et al., 2005).
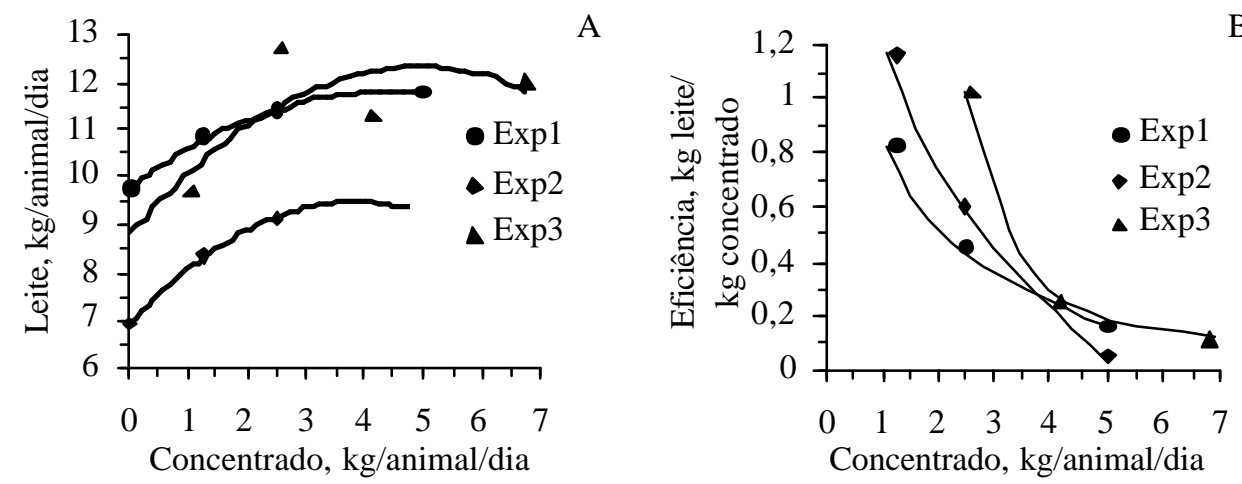

Figura 7 - Produção de leite (A) e eficiência de uso de concentrado (B) em função do consumo de nível crescente de concentrado em três experimentos (Pimentel et al., 2006b, 2006c; Teixeira et al., 2006).

nutrientes específicos sãonecessários,conforme salienta Lana (2003; p.87).

Apesar dos animais responderem de forma curvilínea aos nutrientes, os ganhos de pesos diários estimados pelo nível 1 do NRC (1996) de gado de corte são lineares em função dos consumos de energia e proteína metabolizáveis (Figura 8A). Do mesmo modo, as produções de leite estimadas pelos modelos do CNCPS 5.0 em função dos consumos de energia e proteína metabolizáveis, e NRC (2001) de gado de leite em função dos consumos de energia líquida de lactação e proteína metabolizável, foram lineares pelo uso de níveis crescentes de concentrado (Figura 8B), conforme salienta Lana (2005; p.290-291) e Lana (2007b; p.39 a 43). Portanto, para que estes sistemas sejam compatíveis com as condições tropicais, onde se percebe mais claramente as respostas curvilíneas aos nutrientes, há necessidade de modificações em futuras versões dos mesmos, através da adoção de modelos de saturação cinética.

\section{Produção versus produtividade}

Foram feitos dois estudos para avaliar os fatores que afetam a produção de leite no Brasil, ao nível de fazenda e por estado da federação (Guimarães et al., 2008; Lana et al., 2009). No primeiro caso, foram coletados dados de cinqüenta produtores que vendem leite para um laticínio na região sul do estado do Rio de Janeiro, incluindo dados de produção diária de leite por produtor, com respectivos dados de produção por vaca e por hectare, tamanho da propriedade e da área destinada ao rebanho, total de vacas em lactação e no rebanho, e raça (Tabela 5). No segundo caso, foram coletados dados da EMBRAPA e IBGE nos anos de 2004-2006, em que a ênfase foi na produção de leite por estado em vez de produção por produtor.

A produção de leite em nível de fazenda (primeiro caso) variou de 60 a $4000 \mathrm{~kg} /$ produtor/dia. O aumento na produção de leite foi altamente correlacionado com o número de vacas ordenhadas $(r=0,94)$, seguido de moderação correlação 
com o tamanho da área de pastagem $(\mathrm{r}=0,67)$ e, surpreendentemente, a produtividade por vaca e por unidade de área não correlacionou com a produção de leite por produtor $(\mathrm{r}=0,11$ e 0,06 , respectivamente; Tabela 6$)$. Ao nível nacional (Segundo caso), o resultado repetiu, em que houve alta correlação da produção de leite/estado/ano com o total de vacas em lactação em relação à produtividade de leite $/ \mathrm{km}^{2} /$ ano e leite/vaca/ano $(\mathrm{r}=0,95,0,55$ e 0,51, respectivamente; Tabela 7 ).
Portanto, a produção de leite pelo produtor rural no Brasil é muito mais dependente do tamanho da propriedade e extensões de pastagens, que de índices de produtividade. Acredita-se que o mesmo possa ocorrer na produção de gado de corte e produção agrícola. Sendo assim, os conceitos sobre a produção agrícola precisam ser revistos, frente aos atuais problemas relacionados ao uso inadequado e esgotamento dos recursos naturais não renováveis e poluição ambiental.
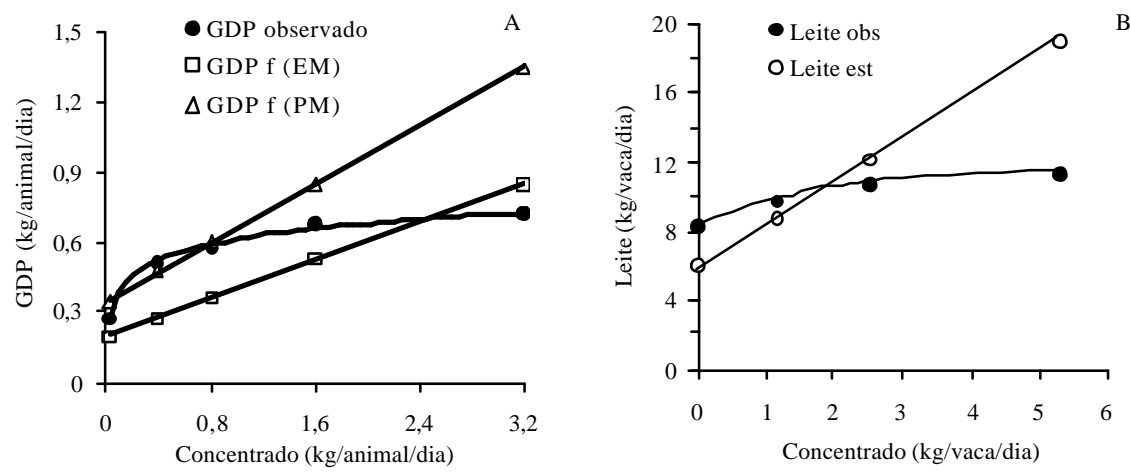

Figura 8 - Ganho de peso médio diário de novilhos em pastagens, observado e estimado pelo nível 1 do NRC (1996) em função do consumo de energia e proteína metabolizável no suplemento (A); e produção de leite observada (média dos dados da Figura 7A) e estimada pelo CNCPS 5.0 e NRC (2001) em função dos consumos de energia metabolizável ou líquida de lactação, respectivamente, e proteína metabolizável $(B)$.

Tabela 5 - Número de produtores, produção média diária de leite por produtor, área destinada ao rebanho, número de animais e de vacas em lactação no rebanho, e produtividade por área e por animal, em função do estrato de produção

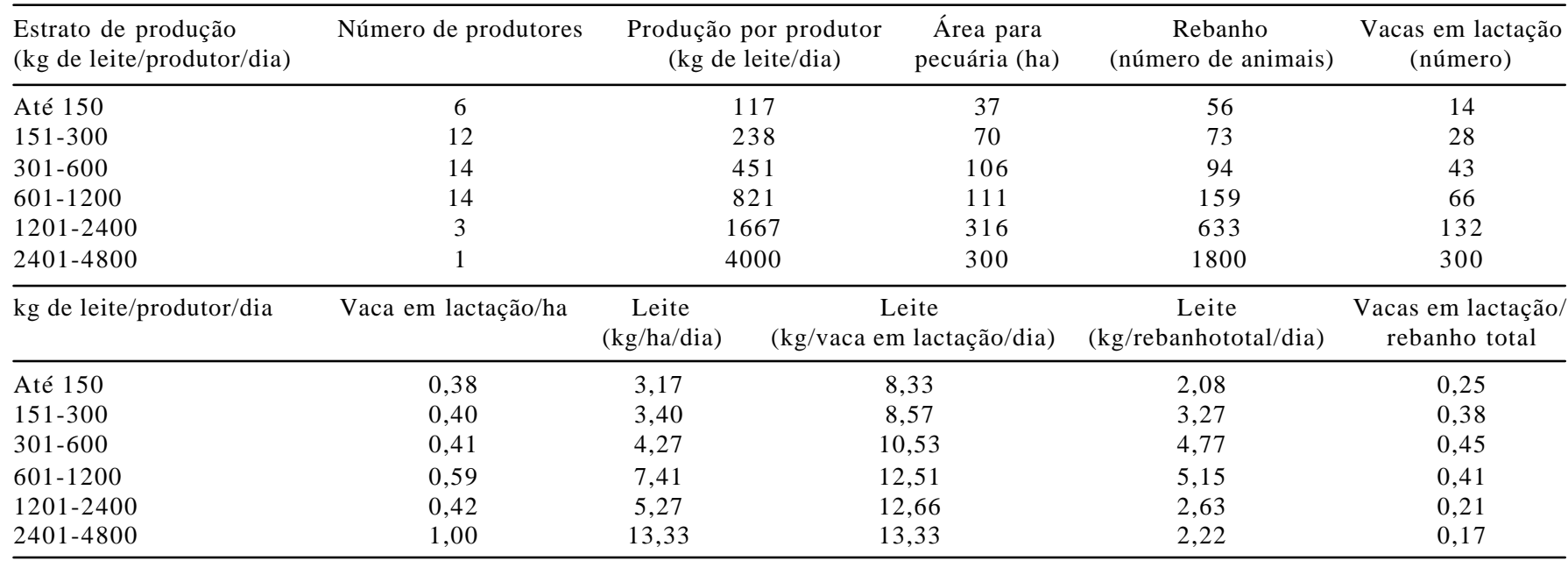

Tabela 6 - Correlação linear da produção diária de leite por produtor com: total de bovinos, total de vacas lactantes, área destinada ao rebanho, tamanho da propriedade e de alguns índices de produtividade (produção diária de leite por hectare e por vaca, vacas em lactação por hectare e produção diária de leite/rebanho total)

\begin{tabular}{|c|c|c|c|}
\hline Parâmetro & Correlação (r) & Parâmetro & Correlação (r) \\
\hline Total de bovinos & 0,94 & Leite $(\mathrm{kg} / \mathrm{ha})$ & 0,13 \\
\hline Total de vacas lactantes & 0,93 & Leite (kg/vaca/dia) & 0,11 \\
\hline Área para o rebanho (ha) & 0,67 & Vaca em lactação/ha & 0,06 \\
\hline Área total da propriedade (ha) & 0,20 & Leite (kg/total de bovinos/dia) & $-0,11$ \\
\hline
\end{tabular}


Tabela 7 - Correlação linear (r) da produção anual de leite pelos estados brasileiros com total de vacas ordenhadas, litros de leite/km²/ ano, litros de leite/vaca/ano e superfície do estado $\left(\mathrm{em} \mathrm{km}^{2}\right)$

\begin{tabular}{|c|c|c|c|c|}
\hline Parâmetro & Litros de leite/estado/ano & Total de vacas ordenhadas & Litros de leite $/ \mathrm{km}^{2} /$ ano & Litros de leite/vaca/ano \\
\hline Total de vacas ordenhadas & 0,95 & & & \\
\hline Litros de leite $/ \mathrm{km}^{2} /$ ano & 0,55 & 0,39 & & \\
\hline Litros de leite/vaca/ano & 0,51 & 0,31 & 0,88 & \\
\hline Superfície do estado $\left(\mathrm{em} \mathrm{km}^{2}\right)$ & 0,11 & 0,21 & $-0,37$ & $-0,26$ \\
\hline
\end{tabular}

\section{Conclusões}

O progresso da agricultura tem com base o aumentoda produtividade animal e de plantas por unidade de área, que só tem aplicação quando terra é o fator limitante. A eficiência de uso dos recursos limitantes deve ser levada em consideração, que incluem ainda a água, os fertilizantes e o petróleo.

Modelos de saturação cinética são ferramentas imprescindíveis para melhorar a eficiência e reduzir os custos de utilização dos recursos naturais não renováveis na agricultura e permitir a conservação destes recursos para as gerações futuras, bem como diminuir os impactos negativos no meio ambiente.

\section{Literatura Citada}

AARON, S. [2005] Some statistics on limited natural resources. Disponível em: <kttp://scotaaron.com/resources2.html> Acesso em: 31/7/2006.

ANGUS, J.F. Modeling N fertilization requirements for crops and pasture. In: BACON, P.E. (Ed.) Nitrogen fertilization in the environment. New York: Marcel Dekker, 1995. p.109127.

BAIK, M.; ASCHENBACH, J.R.; VANDEHAAR, M.J. et al. Effect of dietary protein levels on milk production and nitrogen efficiency in dairy cattle. Journal of Dairy Science, v.89, Suppl. 1, p.81, 2006.

BARGO, F.; MULLER, L.D.; KOLVER, E.S. et al. Invited review: production and digestion of supplemented dairy cows on pasture. Journal of Dairy Science, v.86, n.1, p.1-42, 2003.

BIOTECHNOLOGY AND BIOLOGICAL SCIENCES RESEARCH COUNCIL - BBSRC. Responses in the yield of milk constituents to the intake of nutrients by dairy cows. Wallingford: CAB International, 1998. 96p.

BOLSANELLO, J.; VIEIRA, C.; SEDIYAMA, C.S. et al. Ensaios de adubação nitrogenada e fosfatada no feijão (Phaseolus vulgaris L.) na zona metalúrgica de Minas Gerais.Revista Ceres, v.22, p.423-430, 1975.

BULLOCK, D.G.; BULLOCK, D.S. Quadratique and quadratic-plusplateau models for predicting optimal $\mathrm{N}$ rate for corn. A comparison. Agronomy Journal, v.86, p.191-195, 1994.

BUMB, B.L. World nitrogen supply and demand: an overview. In: BACON, P.E. (Ed.) Nitrogen fertilization in the environment. New York: Marcel Dekker, 1995. p.1-40.

CERRATO, M.E.; BLACKMER, A.M. Comparison of models for describing corn yield response to nitrogen fertilizer. Agronomy Journal, v.82, p.138-143, 1990.

CHAMPE, P.C.; HARVEY, R.A. Biochemistry. 2.ed. Philadelphia: J.B. Lippincott Company, 1994. 443p.
FULKERSON, W.J.; NANDRA, K.S.; CLARK, C.F. et al. Effect of cereal-based concentrates on productivity of Holstein-Friesian cows grazing short-rotation ryegrass (Lolium multiflorum) or Kikuyu (Pennesitum clandestinum) pastures. Livestock Science, v.103, p.85-94, 2006.

GRANLI, T.; BOCKMAN, O.C. Nitrogen oxide from agriculture. Norwegian Journal of Agricultural Sciences, v.12, p.7127, 1994.

GUIMARÃES, G.; LANA, R.P.; GUIMARÃES, A.V. et al. Sustentabilidade da agricultura familiar na produção de leite. In: MINAS LEITE, 10., 2008, Juiz de Fora. Anais... Juiz de Fora: EMBRAPA, 2008. (CD-ROM).

HELYAR, K.R.; POTER, W.M. Soil acidification, its measurement and the processes involved. In: ROBSON, A.D. (Ed.) Soil acidity and plant growth. Sydney: Academic Press, 1989. p.61-100.

HERRING, J.R.; FANTEL, R.J. Phosphate rock demand into the next century: Impact on world food supply. Nonrenewable Resources, v.2, n.3, p.226-246, 1993.

KEANE, M.G.; DRENNAN, M.J.; MOLONEY, A.P. Comparison of supplementary concentrate levels with grass silage, separate or total mixed ration feeding, and duration of finishing in beef steers. Livestock Science, v.103, p.169-180, 2006.

KEBREAB, E.; FRANCE, J.; MILLS, J.A.N. et al. A dynamic model of $\mathrm{N}$ metabolism in the lactating cow and an assessment of impact on $\mathrm{N}$ excretion on the environment. Journal of Animal Science, v.80, p.248-259, 2002.

LANA, R.P. Sistema Viçosa de formulação de rações. 2.ed. Viçosa, MG: UFV, 2003. 90p.

LANA, R.P. Nutrição e alimentação animal (mitos e realidades). Viçosa, MG: UFV, 2005. 344p.

LANA, R.P. Plants responses to nutrients follow a Michaelis-Menten relationship. In: INTERNATIONAL ANNUAL MEETINGS, 2007, New Orleans. Proceedings... New Orleans: ASA, CSSA, SSSA, 2007a. (CD-ROM).

LANA, R.P. Respostas biológicas aos nutrientes. Viçosa, MG: Editora CPD, 2007b. 177p.

LANA, R.P. Plants responses to nutrients follow the saturation kinetic typical of enzyme systems: biological, economical and environmental implications. Online Journal of Biological Sciences, v.8, n.1, p.19-24, 2008.

LANA, R.P.; ABREU, D.C.; CASTRO, P.F.C. et al. Milk production as a function of energy and protein sources supplementation follows the saturation kinetics typical of enzyme systems. In: INTERNATIONAL SYMPOSIUM ON ENERGY AND PROTEIN METABOLISM AND NUTRITION, 2., 2007, Vichy. Proceedings... Vichy, França: European Association for Animal Production, 2007a.

LANA, R.P.; ABREU, D.C.; CASTRO, P.F.C. et al. Kinetics of milk production as a function of energy and protein supplementation. Journal of Animal Science, v.85, Suppl. 1, p.566, 2007b.

LANA, R.P.; GOES, R.H.T.B.; MOREIRA, L.M. et al. Application of Lineweaver-Burk data transformation to explain animal and plant performance as a function of nutrient supply. Livestock Production Science, v.98, p.219-224, 2005.

LANA, R.P.; GUIMARÃES, G.; GUIMARÃES, A.V. et al. Factors affecting milk production in Brazil. Journal of Dairy Science, v.92, Suppl. 1, 2009 (Submetido). 
LEMKE, R.L.; IZAURRALDE, R.C.; MALLEI, S.S. et al. Nitrous oxide emissions from agricultural soils of the Boreal and Parkland regions of Alberta. Soil Science Society of America Journal, v.62, p.1096-1102, 1998.

LINEWEAVER, H.; BURK, D. The determination of enzyme dissociation constants. Journal of the American Chemical Society, v.56, p.658-666, 1934.

MAKOWSKI, D.; WALLACH, D.; MEYNARD, J.-M. Model of yield, grain protein, and residual mineral nitrogen responses to applied nitrogen for winter wheat.Agronomy Journal, v.91, p.377-385, 1999 .

MAKOWSKI, D.; WALLACH, D.; MEYNARD, J.-M. Statistical methods for predicting responses to applied nitrogen and calculating optimal nitrogen rates. Agronomy Journal, v.93, p.531-539, 2001.

MEADOWS, D.H.; MEADOWS, D.L.; RANDERS, J. et al. The limits of growth. A report for the Club of Rome's project on the predicament of mankind. New York: Universe Books, 1972. 205p.

MICHAELIS, L.; MENTEN, M.L. Kinetics of invertase action. Biochemistry Zournal, v.49, p.333-369, 1913.

MITSCHERLICH, E.A. Das gesetz des minimuns und das gesetz des abnehmenden bodenertrages. Landw Jahrb, v.38, p.537-552, 1909.

MALAVOLTA, E. ABC da adubação. 5.ed. São Paulo: Ceres, 1989. 292p.

MOMBIELA, F.; NICHOLAIDES III, J.J.; NELSON L.A. A method to determine the appropriate mathematical form for incorporating soil test levels in fertilizer response models for recommendation purposes. Agronomy Journal, v.73, p.937941, 1981.

MONOD, J. The growth of bacterial cultures. Annual Review of Microbiology, v.3, p.371-394, 1949.

MORGAN, H.P.; MERCER, L.P.; FLODIN, N.W. General model for nutritional responses of higher organisms. Proceedings of the National Academy of Sciences, v.72, n.11, p.43274331, 1975.

NATIONAL RESEARCH COUNCIL - NRC. Nutrient requirements of beef cattle. 7.ed. Washington, DC: National Academy Press, 1996. $242 p$

NATIONAL RESEARCH COUNCIL - NRC. Nutrient requirements of dairy cattle. 7.ed. Washington, $D C$ : National Academy Press, 2001. 381p.

OLIVEIRA, A.J.; LOURENÇO, S.; GOEDERT, W.J. Adubação fosfatada no Brasil. Brasília: EMBRAPA-DID, 1982. 326p.
PIMENTEL, J.J.O.; LANA, R.P.; ZAMPERLINI, B. et al. Milk production as a function of nutrient supply follows a MichaelisMenten relationship. Journal of Dairy Science, v.89, Suppl. 1, p.61, 2006a.

PIMENTEL, J.J.O.; LANA, R.P.; ZAMPERLINI, B. et al. Efeito do teor de proteína e níveis de suplementação com concentrado na produção e composição do leite em vacas leiteiras confinadas. In: REUNIÃO ANUAL DA SOCIEDADE BRASILEIRA DE ZOOTECNIA, 43., 2006, João Pessoa. Anais... João Pessoa: Sociedade Brasileira de Zootecnia, 2006b. (CD-ROM).

PIMENTEL, J.J.O.; LANA, R.P.; ZAMPERLINI, B. et al. P rodução de leite em função de níveis de suplementação com concentrado para vacas leiteiras sob pastejo. In: REUNIÃO ANUAL DA SOCIEDADE BRASILEIRA DE ZOOTECNIA, 43., 2006, João Pessoa-PB. Anais... João Pessoa: Sociedade Brasileira de Zootecnia, 2006c. (CD-ROM).

ROBERTS, T.L.; STEWART, W.M. Inorganic phosphorus and potassium production and reserves. Better Crops, v.86, n.2, p.6-7, 2002.

RUSSELL, J.B. Factors influencing competition and composition of the ruminal bacterial flora. In: GILCHRIST, F.M.C.; MACKIE, R.I. (Eds.) The Herbivore Nutrition in the Subtropics and Tropics. Craighall, South Africa: Science Press, 1984. p.313345.

RUSSELL, J.B. Rumen microbiology and its role in ruminant nutrition. Ithaca: James B. Russell, 2002. 119p.

SAIN, G.E.; JAUREGUI, M.A. Deriving fertilizer recommendations with a flexible functional form. Agronomy Journal, v.85, p.934-937, 1993.

SAIRANEN, A.; KHALILI, H.; VIRKAJARVI, P. Concentrate supplementation responses of the pasture-fed dairy cow. Livestock Science, v.104, n.3, p.292-302, 2006.

STRONG, W.M. Nitrogen fertilization of upland crops. In: BACON, P.E. (Ed.) Nitrogen fertilization in the environment. New York: Marcel Dekker, 1995. p.129-169.

TEIXEIRA, R.M.A; LANA, R.P.; FERNANDES, L.O. et al. Efeito da adição de concentrado em dietas de vacas Gir leiteiro confinadas sob a produção de leite. In: REUNIÃO ANUAL DA SOCIEDADE BRASILEIRA DE ZOOTECNIA, 43., 2006, João Pessoa. Anais... João Pessoa: Sociedade Brasileira de Zootecnia, 2006. (CD-ROM).

Van der PLOEG, R.R.; BÖHM, W.; KIRKHAM, M.B. On the origin of the theory of mineral nutrition of plants and the law of the minimum. Soil Science Society of America Journal, v.63, p.1055-1062, 1999. 